\title{
Single Incision Laparoscopic Cholecystectomy using Conventional Instruments: A Single Institute Experience
}

\author{
Dr. Ashish Thakur ${ }^{1}$, Dr.RS. Jhobta ${ }^{2}$, Dr. Balwant Negi ${ }^{3}$, Dr. Ankit Panwar ${ }^{4 *}$
}

\author{
${ }^{1}$ M.O. General surgery Civil Hospital Rajgarh, Himachal Pradesh, India \\ ${ }^{2}$ Professor Department of General Surgery IGMC Shimla, Himachal Pradesh, India \\ ${ }^{3}$ Assistant Professor Department of General Surgery IGMC Shimla, Himachal Pradesh, India \\ ${ }^{4}$ M.O. General surgery Civil Hospital Rajgarh, Himachal Pradesh, India
}

Article History
Received: 23.02 .2021
Accepted: 08.03 .2021
Published: 12.03 .2021
Journal homepage:
https://www.easpublisher.com

Abstract: Introduction: Laparoscopic Cholecystectomy is the gold standard procedure for symptomatic cholelithiasis for years. Laparoscopic cholecystectomy procedure is refined over years to increase its efficacy, decrease complication rates and increase cosmoses Single incision laparoscopic cholecystectomy being one of them. SILC has some documented advantages in comparison to four ports LC. With use of electrocautery as cutting and dissecting instrument SILC is becoming more popular now days and emerging as a promising surgical technique in treatment of symptomatic cholelithiasis. Methods: Patients of symptomatic cholelithiasis were enrolled in the study and 35 patients underwent electrocautery assisted single incision laparoscopic cholecystectomy. Results were documented in form of duration of surgery, quantity of $\mathrm{CO} 2$ used, intra operative stone spillage, intra operative blood loss, post-operative pain at 6 hour and 24 hour after the surgery, duration of hospital stay, any postoperative complications. Result: Operative time, intra operative blood loss, amount of $\mathrm{CO}_{2}$ used, post-operative pain score at 24 hour, intraoperatively stone spillage, all parameters were found to be statistically significant except for post-operative pain score at 6 hours, post-operative complications and conversion into 4 port/2 port /open cholecystectomy which were not statically significant. Conclusion: SILC is emerging as a promising technique for symptomatic cholelithiasis with use of conventional instruments. There is no increase in the cost of procedure and there is increase benefit of cosmoses. Hence making it a suitable and promising technique for symptomatic cholelithiasis.

Keywords: Laparoscopic Cholecystectomy Conventional Instruments.

Copyright (C) 2021 The Author(s): This is an open-access article distributed under the terms of the Creative Commons Attribution 4.0 International License (CC BY-NC 4.0) which permits unrestricted use, distribution, and reproduction in any medium for non-commercial use provided the original author and source are credited.

\section{INTRODUCTION}

Prof Dr Erich Mühe of Germany performed the first laparoscopic cholecystectomy (LC). The first reports of SILC came in 1997 in a letter to the editor in the British Journal of Surgery by Navarra [1], Piskun reported on 10 patients on whom he performed a SILS cholecystectomy by placing two 5-mm trocars through a common umbilical incision and using transabdominal sutures to manipulate the gallbladder [2]. The fascial bridge between the two trocars was then joined and the specimen extracted through this single umbilical incision.

At present, monopolar electrocautery is the main cutting method used for gallbladder dissection from the liver bed. It is associated with local thermal and distant tissue damage, which might cause inadvertent perforation of the gallbladder during gallbladder bed dissection [3]. However easy use of electrocautery, easy availability and reduced cost make it a suitable instrument for dissection. Electrocautery is used as a dissecting instrument in SILC and results are obtained as per following parameters
1. Operative time
2. Bleeding time
3. Length of hospital stay
4. Spillage of stones
5. Conversion into open cholecystectomy
6. Pain score post operatively
7. Amount of $\mathrm{CO} 2$ used.

\section{MethodS}

All consecutive patients of symptomatic cholelithiasis confirmed by USG reporting and all patients are operated by same team of surgeons in the Department of General Surgery, IGMC Shimla.

\section{Inclusion criteria for our study were \\ 1. Age between 21 and 80 \\ 2. ASA score of $<3$ \\ 3. Symptomatic Gall stones}


Patients in one of the following groups were considered as high risk patients and were not included in the study.

1. Patient with BMI $>40$

2. Patient with choledocholithiasis with cholelithiasis

3. Previous upper abdominal surgery

4. Patient with bleeding disorder

5. Acute cholecystitis

6. Patient on warfarin

7. Patient not willing to participate in Study.

All eligible patients underwent single incision laparoscopic cholecystectomy using conventional instruments by technique as described below-

SILC performed with the help of 2 slings of sutures, which included following steps:

1. Under general anesthesia, a $15-20 \mathrm{~mm}$ (approximately) curvilinear skin incision made through the inner margin of the umbilicus. Subcutaneous tunnelling was done on either side to avoid scissoring of instruments. Pneumoperitoneum was created via closed method and set at pressure of 12 $\mathrm{mmHg}$. Two $10 \mathrm{~mm}$ trocar, one for $10 \mathrm{~mm} 30$ degree laparoscope and one trocar as a working port were inserted through incision.

2. Fundus of gall bladder was retracted with the help of a suture using a straight needle, which was inserted through right 8 th intercostal space in the anterior axillary line .Needle was passed through seromuscular layer of the gallbladder fundus and pulled toward the anterior abdominal wall. This suture was used for retraction by the assistant.

3. Hartmann's pouch was punctured and retracted using the second suture which was inserted in the epigastrium and taken out through the right hypochondrium to expose calot's triangle.

4. Electrocautery was used for calots triangle dissection. Cystic artery and duct were skeletonised and liga clips were applied. Sectioning was performed with application of harmonic ace on minimum position. The gallbladder dissection from the liver bed was carried out using electrocautery from the infundibulum to the fundus.

5. Extraction of gall bladder was done through 10 $\mathrm{mm}$ trocar after removal of the suspending sutures from the abdominal wall. The umbilical incision was closed with subcuticular sutures or metal clips.

The following parameters were recorded in each groupA. Intraoperative Parameters

1. Operative findings including status of gall bladder, presence of adhesions, any intra operative stone spillage.

2. Operative time calculated (in minutes) for all cases from skin incision to skin closure

3. Bleeding-Assessed through gauge visual analogue method- \% saturation of gauge piece

\begin{tabular}{|l|l|l|l|l|}
\hline Size of gauge in c.m. & 25\% soaked & 50\% soaked & 75\% soaked & 100\% soaked \\
\hline $10 \times 10$ & $3 \mathrm{~m} .1$. & $6 \mathrm{~m} .1$. & $9 \mathrm{~m} .1$. & $12 \mathrm{~m} .1$. \\
\hline $30 \times 30$ & $25 \mathrm{~m} .1$. & $50 \mathrm{~m} .1$. & $75 \mathrm{~m} .1$. & $100 \mathrm{~m} .1$. \\
\hline $45 \times 45$ & $40 \mathrm{~m} . \mathrm{l}$. & $80 \mathrm{~m} .1$. & $120 \mathrm{~m} .1$. & $160 \mathrm{~m} .1$. \\
\hline
\end{tabular}

4. Quantity of $\mathrm{CO}_{2}$ used

5. Use of drain

6. Conversion to Open Cholecystectomy/double port/four port cholecystectomy
B. Postoperative Parameters

1. Postoperative pain at $6 \mathrm{~h}$ and $24 \mathrm{~h}$ after surgery using visual analogue scale (VAS) used and the requirement of post-operative analgesics was noted.

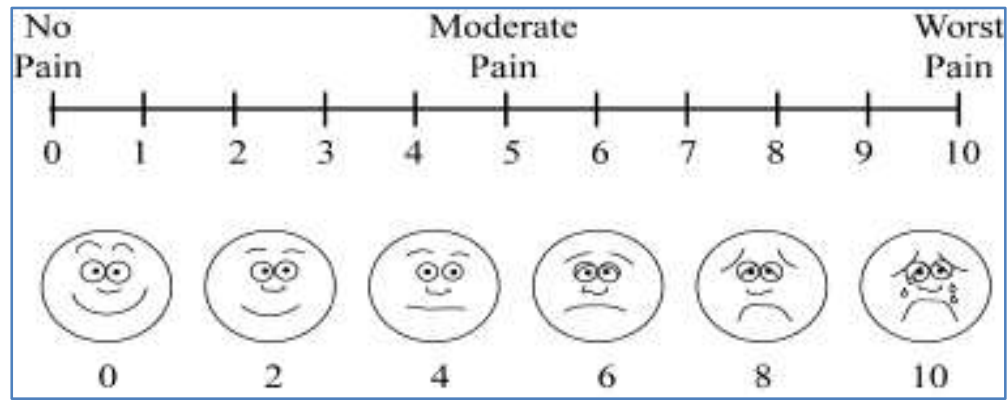

(C) East African Scholars Publisher, Kenya 
Correlation between Visual and verbal scale:

1-3 = mild pain

4-6 = moderate pain

$7-10=$ severe pain

2. Length of Hospital Stay (in days)

3. Any postoperative complications

Data collected, cleaned and entered into excel spread sheet.

1. Expressions of discrete variables were as percentages or proportions.

2. Chi-Square test was used to study difference in distribution of discrete variables.

3. Expression of continuous variables were as Mean + SD or median + Interquartile range.

4. Significance of difference in continuous variables was analysed using Student $\mathrm{T}$ test or Wilcoxon Signed Rank Test depending on distribution of variables.

5. For all statistical analysis two tailed tests were used.

\section{Age distribution}

\begin{tabular}{|l|l|}
\hline PARAMETERS OBSERVED & Mean value \\
\hline Operative Time(min) & 52 \\
\hline $\mathrm{CO}_{2}$ Used ( L) & 40.8 \\
\hline Blood loss ( ml) & 101.2 \\
\hline Intraoperative stone spillage(no. of cases) & 14 \\
\hline Conversion to four/double port/open cholecystectomy(no. of cases) & 3 \\
\hline Pain score at 6 hour & 6.32 \\
\hline Pain score at 24 hour & 2.8 \\
\hline Length of hospital stay(days) & 2.7 \\
\hline Post op complication & 2 \\
\hline
\end{tabular}

Mean operative time for is $52 \pm 17.2 \mathrm{~min}$.

In terms of $\mathrm{CO}_{2}$ used mean $\mathrm{CO}_{2}$ used is $40.8 \pm 15.4$ litres. Mean blood loss is $101.24 \pm 98.1 \mathrm{ml}$.

Mean stay in hospital is $2.78 \pm 2.81$ days.

Average pain score at 6 hours and 24 hours is 6.32 and

2.8 respectively.

In terms of stones spillage, 14 patients had intra operative stone spillage.

3 cases are converted to open and 2 cases developed post-operative complications.

\section{DiscuSSION}

There are many studies in which four port laparoscopic cholecystectomy using conventional instruments is compared with laparoscopic cholecystectomy using harmonic ace. But as our study is based on single incision laparoscopic
Data was analysed using Epi - info version 7.2.2. P value $<0.05$ was considered as statistically significant.

At the end of study data was compiled and outcome parameters were studied as follows:

- Duration of surgery

- Quantity of CO2 used

- Intra operative stone spillage

- Intra operative blood loss

- Post-operative pain at 6 hour and 24 hour after the surgery

- Duration of hospital stay

- Any postoperative complications

\section{Results}

Out of 35 patients, 5 patients were male and 30 were female. All underwent electrocautery assisted dissection. cholecystectomy there is only limited data for discussion. However different parameters are discussed as follows and data from different studies (four port laparascopic cholecystectomy based studies) is incorporated in the discussion. Operating time was 64.7 \pm 13.74 in the study conducted by Jain et al. and in Kadil et al. study it was $61.88 \pm .1716$ [4, 5]. Huscher et al. [6] and Bessa et al. [7] suggest a significant reduction in blood loss in four port laparoscopic cholecystectomy, by use of harmonic ace instead of use of conventional instrument that is electrocautery. Kandil et al showed in their study that the risk of GB perforation was $18.6 \%$ [5]. Risk of GB perforation was not found significantly raised in the study conducted by Mukesh et al. [8]. Mahabaleshwar et al. revealed a 14.23 times greater risk of GB perforation with use of conventional instruments [9]. Post-operative pain score after 24 hours in the study 
conducted by Kandil et al. was $4.48 \pm 1.89$ [5]. El Nakeeb et al. suggest conversion rate with the use of conventional instruments was 5\%. Guanqun et al. [10] shows mean stay in hospital after surgery as 3.0 \pm 0.4 with the use of conventional instruments. Gelmini et al. [11] shows mean post-operative hospital stay as 2 days. Guanqun et al. Show no significant postoperative complications same as our study.

\section{Conclusion}

Gall stones poses major burden on modern day health care facilities. Large number of surgeries is performed in our centre on daily basis. SILC being performed in our centre on regular basis so operative time is now comparable to four port laparoscopic cholecystectomy, it has got advantage in term of decrease post-operative pain and hospital stay, so burden on health care system is decreased. SILC using conventional instruments is cost effective method of cholecystectomy. Conventional instruments are easily available, easy to use and learning curve is less. Although there are some disadvantages of using conventional instruments and so is the search for ideal instrument for cholecystectomy being going on. But in the present scenario cholecystectomy using conventional instruments is the best cost effective treatment modality.

\section{REFERENCES}

1. Navarra, G., Pozza, E., Occhionorelli, S., Carcoforo, P., \& Donini, I. (1997). One-wound laparoscopic cholecystectomy. British Journal of Surgery, 84(5), 695-695.

2. Piskun, G., \& Rajpal, S. (1999). Transumbilical laparoscopic cholecystectomy utilizes no incisions outside the umbilicus. Journal of Laparoendoscopic \& Advanced Surgical Techniques, 9(4), 361-364.

3. Morino, M. (2003). Randomized clinical trial of ultrasonic versus electrocautery dissection of the gallbladder in laparoscopic cholecystectomy.
4. Jain, S. K., Tanwar, R., Kaza, R. C. M., \& Agarwal, P. N. (2011). A prospective, randomized study of comparison of clipless cholecystectomy with conventional laparoscopic cholecystectomy. Journal of Laparoendoscopic \& Advanced Surgical Techniques, 21(3), 203-208.

5. Kandil, T., El Nakeeb, A., \& El Hefnawy, E. (2010). Comparative study between clipless laparoscopic cholecystectomy by harmonic scalpel versus conventional method: a prospective randomized study. Journal of Gastrointestinal Surgery, 14(2), 323-328.

6. Hüscher, C. G. S., Lirici, M. M., Di Paola, M., Crafa, F., Napolitano, C., Mereu, A., ... \& Amini, M. (2003). Laparoscopic cholecystectomy by ultrasonic dissection without cystic duct and artery ligature. Surgical Endoscopy And Other Interventional Techniques, 17(3), 442-451.

7. Bessa, S. S., Al-Fayoumi, T. A., Katri, K. M., \& Awad, A. T. (2008). Clipless laparoscopic cholecystectomy by ultrasonic dissection. Journal of Laparoendoscopic \& Advanced Surgical Techniques, 18(4), 593-598.

8. Mukesh, K. S., Vijayata, S., Mohinder, K. G., \& Deepak, S. (2017). Triple ligation technique of clipless laparoscopic cholecystectomy: a spanner especially for complicated cholecystitis. Int $J A d v$ Med, 4, 1358-1363.

9. Mahabaleshwar, V., Kaman, L., Iqbal, J., \& Singh, R. (2012). Monopolar electrocautery versus ultrasonic dissection of the gallbladder from the gallbladder bed in laparoscopic cholecystectomy: a randomized controlled trial. Canadian journal of surgery, 55(5), 307.

10. Liao, G., Wen, S., Xie, X., \& Wu, Q. (2016). Harmonic scalpel versus monopolar electrocauterization in cholecystectomy. JSLS: Journal of the Society of Laparoendoscopic Surgeons, 20(3).

11. Gelmini, R., Franzoni, C., Zona, S., Andreotti, A., \& Saviano, M. (2010). Laparoscopic cholecystectomy with Harmonic scalpel. JSLS: Journal of the Society of Laparoendoscopic Surgeons, 14(1), 14.

Cite This Article: Ashish Thakur et al (2021). Single Incision Laparoscopic Cholecystectomy using Conventional Instruments: A Single Institute Experience. East African Scholars J Med Sci, 4(3), 62-65. 